\title{
PENGUCAPAN TEKS BAHASA INDONESIA OLEH MAHASISWA FILIPINA: KAJIAN FONOLOGI
}

\author{
Catharina Dian Ikawati Susilo, Dian Indira \\ Universitas Padjadjaran \\ Email: cathrinasusilo@gmail.com,dian.indira@unpad.co.id
}

\begin{abstract}
Abstrak: Sering dijumpai perubahan pengucapan fonem-fonem bahasa Indonesia oleh orangorang asing. Penelitian ini bertujuan untuk mendeskripsikan pengucapan fonem pada pasangan kata yang memuat pasangan minimal fonem dan teks berbahasa Indonesia oleh mahasiswa asal Filipina. Penelitian dilakukan dengan metode kualitatif deskriptif dengan pendekatan analisis kontrastif. Data yang digunakan adalah korpus pengucapan pasangan kata dan pembacaan teks pendek dalam bahasa Indonesia. Metode yang digunakan adalah teknik simak libat cakap (SLC). Pada penelitian ini, analisis data difokuskan pada klasifikasi identitas fonem berdasarkan bagianbagian alat bicara yang menghasilkannya. Hasil penelitian menunjukkan adanya perubahan pengucapan fonem konsonan $/ \mathrm{r} / / \mathrm{s} / / \mathrm{n} / / \mathrm{g} /$ dan $/ \mathrm{k} /$ diucapkan dengan tekanan nada yang kuat, perubahan pengucapan vokal /o/ yang juga diucapkan secara kuat pada posisi yang seharusnya diucapkan lemah, serta vokal /e/ tidak dibaca sebagai /e/ melainkan dengan / $/$ /. Selain itu, ditemukan adanya fenomena penambahan fonem serta metatesis gabungan fonem dalam satu kata.
\end{abstract}

Kata Kunci: fonologi, pengucapan fonem, bahasa Indonesia, penutur Filipina.

\section{INDONESIAN TEXT PRONOUNCIATION BY PHILIPPINES STUDENTS: A STUDY OF PHONOLOGY}

\begin{abstract}
Foreigners often see changes in the pronunciation of Indonesian phonemes. This study aims to describe the pronunciation of phonemes in word pairs containing a minimum pair of phonemes and Indonesian-language text by students from the Philippines. The research was conducted using a descriptive qualitative method with a contrastive analysis approach. The data used are the corpus of pronouncing words and reading short texts in Indonesian. The method used was the listening competent listening technique (SLC). In this study, data analysis is focused on the classification of phoneme identities based on the parts of the speech instrument that produce them. The results showed that there was a change in the pronunciation of the consonant phoneme / $\mathrm{r} / \mathrm{s} /$ $/ \mathrm{n} / / \mathrm{g} /$ and / $\mathrm{k} /$ pronounced with a strong tonal stress, a change in the pronunciation of the / o / vowel which was also pronounced strongly in a position that should have been pronounced weak, and vowel / e / is not read as / e / but as / $\varepsilon$ /. In addition, the phenomenon of adding phonemes and metathesis of combined phonemes in one word was found
\end{abstract}

Keywords: phonology, phoneme pronunciation, Indonesian, Filipino speakers.

\section{PENDAHULUAN}

Bahasa adalah suatu sistem lambang bunyi yang dipakai manusia untuk tujuan komunikasi (Samsuri,
1985). Pengajaran bahasa Indonesia pada hakikatnya mempunyai ruang lingkup dan tujuan yang menumbuhkan dan mengembangkan

BASASTRA Jurnal Bahasa, Sastra, dan Pengajarannya

Volume 9 Nomor 1, April 2021, P-ISSN 2302-6405, E-ISSN 2714-9765 
kemampuan mengungkapkan pikiran dan perasaan dengan menggunakan bahasa yang baik dan benar agar seseorang dapat berkomunikasi secara tertulis maupun lisan dengan baik dan benar. Sebagai alat komunikasi secara lisan, bahasa dapat ditinjau dari aspek fonologis, morfologis, sintaksis, semantik maupun aspek lainnya.

Istilah fonologi ini berasal dari gabungan dua kata Yunani yaitu phone yang berarti bunyi dan logos yang berarti ilmu. Jadi secara harfiah, fonologi adalah ilmu tentang bunyi. Akan tetapi, bunyi yang dipelajari dalam fonologi bukan bunyi sembarang bunyi, melainkan bunyi bahasa yang dapat membedakan arti dalam bahasa lisan ataupun tulis yang digunakan oleh manusia. Bunyi yang dipelajari dalam fonologi kita sebut dengan istilah fonem.

Penyelidikan mengenai fonologi yang, di dalamnya mencakup fonemik dan fonetik, bahasa perlu dilakukan, salah satunya untuk mengetahui ilmu budaya dan pemakaiannya. Tanpa memahami ilmu bunyi tidak akan mendapatkan hasil yang sempurna dan tidak memuaskan karena bahasa pertama-tama bersifat bunyi (fonetis). Menurut Samsuri (1985: 91), fonetik merupakan ilmu bunyi. Adapun menurut Gross (1998: 36) fonetik merupakan suatu ilmu alam yang berdasar pada anatomi, psikologi, fisika (akustik), dan matematika. Dasar penelitiannya adalah bahan suara sehingga bunyi-bunyi bahasa asing yang menyimpang dari kaidah bahasa dapat diklasifikasikannya dan ditunjukkannya fungsi hubungan dari yang satu dengan yang lain.

Gross (1998) membagi fonetik menjadi tiga dasar, yaitu: (1) fonetik artikulatoris, yaitu dipelajari dari produksi bunyi oleh alat bicara, termasuk dalam jenis dan tempat pengartikulasian; (2) fonetik akutis, yaitu menyangkut lama, frekuensi, dan intensitas; dan (3) fonetik auditoris, yaitu berkaitan dengan penerimaan dan analisis data yang diterima melalui pendengaran.

Secara fonetis, bahasa yang dapat dianggap merupakan kesatuan bunyi dipelajari melalui tiga macam jalan, yaitu: bagaimana bunyi itu dihasilkan oleh alat-alat ucap, bagaimana arus bunyi yang telah keluar dari rongga mulut dan/atau rongga hidung si pembicara merupakan gelombang-gelombang bunyi udara, bagaimana bunyi itu diindrakan melalui alat pendengar dan syaraf pendengar (Samsuri, 1985: 9293).

Secara sederhana semua alat ucap manusia dapat dibandingkan dengan alat musik tiup seperti seruling: bunyi-bunyi dihasilkan dengan mengembuskan udara yang dihambat, dihalangi, atau lain-lainnya yang merintangi kebebasan jalannya arus udara melalui aliran yang terkurung. Adapun artikulasi menurut Samsuri (1985) dibagi menjadi (1) bunyi vokoid, yaitu relatif tidak ada 
hambatan atau rintangan antara paruparu dan udara keluar dan (2) bunyi kontoid, yaitu bunyi yang terdapat hambatan atau rintangan antara paruparu dan udara luar.

Kegunaan hasil penyelidikan fonem-fonem suatu bahasa secara langsung adalah untuk mengembangkan sistem tulisan yang merepresentasikan atau menyatakan ujaran bahasa tersebut. Hal yang mungkin terdapat kesukaran, yaitu banyak faktor-faktor bunyi tidak dinyatakan oleh tulisan itu, karena suatu sistem tulisan memang tidak pernah "sempurna" dalam arti memakai kriteria: satu fonem, satu tanda. Di samping itu, fonologi bertujuan untuk mencari seperangkat tanda-tanda untuk untuk menyatakan ujaran bahasa. Lalu merangkum fasilitas-fasilitas yang diberikan oleh masyarakat bahasa tersebut.

Yang menjadi tujuan penelitian adalah (1) mendeskripsikan pengucapan kata-kata oleh orang Filipina yang memuat pasangan minimal fonem, kata-kata yang memuat deretan konsonan atau fonotaktik tertentu, serta kata-kata dengan suku tertutup pada bagian akhirnya, dan (2) mengidentifikasi perbedaan pengucapan fonem-fonem bahasa Indonesia oleh orang asing tersebut.

Telah banyak kajian realisasi bahasa Indonesia oleh orang asing yang sedang belajar bahasa Indonesia dari aspek fonologi. Misalnya penelitian yang dilakukan Adityarini,
Pastika, \& Sedeng (2019) tentang interferensi fonologis pada pembelajar BIPA (bahasa Indonesia oleh penutur asing) asal Eropa yang tinggal di Bali. Hasil penelitiannya menunjukkan bahwa interferensi fonologi yang terjadi pada pemelajar BIPA asal Eropa di Bali, yaitu berupa interferensi bunyi vokal (terjadi pada vokal [a], [u], dan [ə]), interferensi bunyi konsonan (terjadi pada konsonan [r], [y], dan [t]), interferensi berupa penambahan bunyi (terjadi pada bunyi [y] dan [n]), dan interferensi berupa penghilangan bunyi (terjadi pada konsonan [r], deret vokal [e] dan [a], serta konsonan [h]). Interferensi ini terjadi karena adanya perbedaan bunyi vokal dan bunyi konsonan dalam bahasa Indonesia dan bahasa Inggris. Selain itu, interferensi ini juga disebabkan oleh adanya perbedaan pelafalan sebuah bunyi vokal atau bunyi konsonan yang sama pada kedua bahasa tersebut.

Penelitian sejenis yang lain adalah yang dilakukan Inderasari \& Agustina (2017) dengan fokus kesalahan pemakaian bahasa Indonesia oleh mahasiswa BIPA dari Thailand. Yang membedakan penelitian ini dengan kedua penelitian tersebut adalah sumber data informan pada penelitian ini tidak mengikuti kelas BIPA, tetapi seorang misionaris yang sedang belajar teologi di Bandung sehingga tidak mengikuti pendidikan bahasa Indonesia secara formal. Dengan demikian, hasil penelitian ini 
memungkinkan untuk dikomparasikan dengan hasil penelitian sebelumnya dalam hal fonologi ditinjau dari perbedaan pengalaman belajar bahasa Indonesia yang dilakukan secara formal dan nonformal.

\section{METODE}

Penelitian dilakukan dengan metode kualitatif deskriptif. Penelitian ini menggunakan pendekatan kualitatif karena data diuraikan dan dijelaskan dari aspek-aspek fonologi dalam bahasa Indonesia dengan melampirkan bukti pengucapan teks bahasa Indonesia oleh orang asing yang mempelajari bahasa Indonesia tingkat dasar. Pendekatan penelitian yang diterapkan adalah analisis kontrastif, yaitu membandingkan pelafalan fonem oleh orang asing dengan lafal fonem baku bahasa Indonesia.

Data lisan berupa pengucapan fonem-fonem pada pasangan kata yang berbeda satu fonem dan pembacaan teks secara bersuara kepada informan, yaitu mahasiswa asing di UNPAR, Bandung. Informan tersebut bernama Fra Donald yang berasal dari Mindanau, Filipina yang sedang belajar bahasa Indonesia sebagai bahasa asing. Informan telah mempelajari bahasa Indonesia lisan selama enam bulan.

Teknik pengumpulan data dilakukan dengan teknik simak libat cakap (SLC), yaitu dengan meminta informan mengucapkan kata-kata yang merupakan pasangan minimal dan membaca bersuara kata tertentu pada teks berbahasa Indonesia. Pengumpulan data juga dilakukan dengan teknik perekaman dan pencatatan, yaitu peneliti merekam dengan video pengucapan kata dan pembacaan teks oleh informan serta mencatat tambahan informasi yang berkaitan dengan data. Selanjutnya, rekaman pengucapan kata dan pembacaan teks ditranskripsikan secara fonetis untuk memudahkan proses analisis.

Teknik analisis data yang digunakan adalah teknik fonetis artikulatoris, yaitu mengklasifikasi data berdasarkan bagian alat bicara yang aktif ketika menghasilkan suatu fonem, baik konsonan maupun vokal. Misalnya fonem /d/ pada kata dari diklasifikasikan sebagai fonem apikopalatal, yang artinya apex atau ujung lidah sebagai artikulator (bagian alat bicara yang aktif), sedangkan dent atau gigi sebagai titik artikulasi atau bagian alat bicara yang pasif. Fonem /t/ pada kata tari sebagai fonem apikodental yang artinya apex atau ujung lidah sebagai artikulator (bagian alat bicara yag aktif), sedangkan palatum atau langit-langit keras sebagai titik artikulasi atau bagian alat bicara yang pasif. Selain itu, didasarkan dari ada tidaknya hambatan saat fonem diucapkan, fonem /d/ dan /t/ diklasifikasikan sebagai fonem hambat atau plosif karena karena adanya hambatan aliran udara saat diucapkan. 


\section{HASIL DAN PEMBAHASAN}

Pada hasil penelitian ini disajikan transkripsi fonetis data pengucapan fonem pasangan minimal pada pasangan kata dan pembacaan teks berbahasa Indonesia. Ada 5 pasangan kata yang memuat pasangan minimal, yaitu dua kata yang memiliki satu fonem berbeda, sedangkan semua fonem lainnya sama. Misalnya pasangan kata dari - tari yang mana memiliki satu fonem berbeda, yaitu /d/ dan /t/, sedangkan 3 fonem lainnya sama, yaitu /a, r, i/. Adapun 5 pasangan kata tersebut adalah sebagai berikut ini.

$$
\begin{aligned}
& \text { garis - baris } \\
& \text { tahan - lahan } \\
& \text { misa - bisa } \\
& \text { pagar - pakar } \\
& \text { pohon - mohon }
\end{aligned}
$$

Adapun teks yang disediakan untuk dibaca secara bersuara adalah berupa cerita rakyat sebagai berikut ini. Informan tidak diminta membaca semua kata pada teks, tetapi hanya kata tertentu yang memiliki fonotaktik (jejeran fonem dalam kata) yang memiliki deretan beberapa konsonan dengan pola tertentu, dari yang sederhana sampai yang kompleks.

Pada zaman dahulu, hiduplah sepasang suami istri petani. Mereka tinggal di sebuah desa di dekat hutan. Mereka hidup bahagia. Sayangnya mereka belum saja dikaruniai seorang anak pun. Setiap hari mereka berdoa pada Yang Maha Kuasa. Mereka berdoa agar segera diberi seorang anak. Suatu hari seorang raksasa melewati tempat tinggal mereka. Raksasa itu mendengar doa suami istri itu. Raksasa itu kemudian memberi mereka biji mentimun.

"Tanamlah biji ini. Nanti kau akan mendapatkan seorang anak perempuan," kata Raksasa. "Terima kasih, Raksasa," kata suami istri itu. “Tapi ada syaratnya. Pada usia 17 tahun anak itu harus kalian serahkan padaku," sahut Raksasa. Suami istri itu sangat merindukan seorang anak. Karena itu tanpa berpikir panjang mereka setuju.

Suami istri petani itu kemudian menanam biji-biji mentimun itu. Setiap hari mereka merawat tanaman yang mulai tumbuh itu dengan sebaik mungkin. Berbulan-bulan kemudian tumbuhlah sebuah mentimun berwarna keemasan. Buah mentimun itu semakin lama semakin besar dan berat. Ketika buah itu masak, mereka memetiknya. Dengan hati-hati mereka memotong buah itu. Betapa terkejutnya mereka, di dalam buah itu mereka menemukan bayi perempuan yang sangat cantik. Suami istri itu sangat bahagia. Mereka memberi nama bayi itu Timun Mas. Tahun demi tahun berlalu. Timun Mas tumbuh menjadi gadis yang cantik. Kedua orang tuanya sangat bangga padanya. Tapi mereka menjadi sangat takut. Karena pada ulang tahun Timun Mas yang ke-17, sang raksasa datang 
kembali. Raksasa itu menangih janji untuk mengambil Timun Mas.

\section{Transkripsi Fonetis Data}

Berikut adalah transkripsi pengucapan pasangan kata dari rekaman video pertama yang memuat pasangan minimal oleh narasumber.

Data 1:

garis baris

$[/ \mathrm{g} / / \mathrm{a} / / \mathrm{r} / / \mathrm{i} / / \mathrm{s} /]-[/ \mathrm{b} / / \mathrm{a} / / \mathrm{r} / \mathrm{i} / / \mathrm{s} /]$

Data 2:

tahan lahan

$[/ \mathrm{t} / / \mathrm{a} / / \mathrm{h} / / \mathrm{a} / / \mathrm{n} /]-[/ \mathrm{l} / / \mathrm{a} / / \mathrm{h} / / \mathrm{a} / / \mathrm{n} /]$

Data 3:

misa bisa

$[/ \mathrm{b} / / \mathrm{c} / / \mathrm{s} / / \mathrm{a} /]-[/ \mathrm{b} / / \varepsilon / / \mathrm{s} / / \mathrm{a} /)$

Data 4:

pagar pakar

$[/ \mathrm{p} / / \mathrm{a} / / \mathrm{g} / / \mathrm{a} / / \mathrm{r} /]-[/ \mathrm{p} / / \mathrm{a} / / \mathrm{k} / / \mathrm{a} / / \mathrm{r} /]$

Data 5:

pohon mohon

$[/ \mathrm{p} / / \mathrm{o} / / \mathrm{h} / / \mathrm{o} / / \mathrm{n} /]-[/ \mathrm{m} / / \mathrm{o} / / \mathrm{h} / / \mathrm{o} / / \mathrm{n} /]$

Data di atas menunjukkan bahwa pengucapan beberapa fonem konsonan /r/ pada data 1 , /s/ pada data 1 dan 3 , $/ \mathrm{n} /$ pada data 2 dan 5 , serta $/ \mathrm{g} /$ dan $/ \mathrm{k} /$ pada data 4 diucapkan dengan tekanan nada yang kuat. Hal tersebut berbeda dengan penutur bahasa Indonesia yang tidak diucapkan dengan tekanan yang kuat. Selain itu, pengucapan fonem $/ \mathrm{m} /$ dengan identitas yang sama dengan fonem /b/. Adapun pada pengucapan vokal juga ada perbedaan, yaitu pada data 1 vokal /i/ pada kata baris - garis dalam posisi suku tertutup diucapkan sebagai /i/ kuat. Padahal bagi penutur asli Indonesia, fonem /i/ pada kata-kata tersebut diucapkan secara lemah atau yang biasa disimbolkan dengan /I/. Demikian halnya pada data 5, vokal /o/ pada pohon-mohon yang juga dilafalkan dengan kuat. Padahal, pada posisi seperti itu, yaitu /o/ yang berjajar pada dua suku berurutan oleh penutur asli bahasa Indonesia diucapkan sebagai $/ \mathrm{O} /$.

Untuk data transkripsi fonetis pembacaan teks berbahasa Indonesia dari rekaman video kedua, tidak semuanya disajikan di sini, namun hanya pengucapan kata yang berbeda dengan pengucapan pada penutur asli bahasa Indonesia sebagai berikut ini.

Data 6

Pada zaman dahulu, hiduplah $[/ \mathbf{h} / / \mathbf{i} / / \mathbf{d} / / \mathbf{u} / / \mathbf{p} / / \mathbf{h} / / \mathbf{a} / / \mathbf{h} /]$

Data 7

sepasang suami istri [/i//s//t//r// $/ \mathbf{e}]$ petani. Mereka tinggal di sebuah desa di dekat

Data 8

hutan $[/ \mathbf{h} / / \mathbf{u} / / \mathbf{l} / \mathbf{a} / / \mathbf{t} /]$.

Mereka hidup bahagia. Sayangnya

Data 9

mereka belum saja $[/ \mathbf{s} / / \mathbf{a} / / \mathbf{h} / / \mathbf{a} /]$

Data 10

dikaruniai [/d/ /i/ / $/ \mathbf{k} / \mathbf{a} / / \mathbf{r} / / \mathbf{u} / / \mathbf{n} / / \mathbf{i} / / \mathbf{a} /]$ seorang anak pun. 
Data 11

Setiap $[/ \mathbf{s} / / \mathbf{\varepsilon} / / \mathbf{t} / \mathbf{i} / / \mathbf{a} / / \mathbf{p} / / \mathbf{a} /]$ hari mereka berdoa

Data 12

pada [/d//a//p//a/] Yang Maha Kuasa.

Data 13

Mereka berdoa $[/ \mathbf{b} / / \mathbf{\varepsilon} / / \mathbf{r} / / \mathbf{d} / / \mathbf{o} / / \mathbf{w} / / \mathbf{a} /]$

agar segera diberi seorang anak.

Data 14

Suatu $[/ \mathbf{s} / / \mathbf{u} / / \mathbf{a} / / \mathbf{t} / / \mathbf{a} /]$

hari seorang raksasa melewati tempat

Data 15

tinggal $[/ \mathbf{t} / \mathbf{i} / / \mathbf{y} / / \mathbf{g} / / \mathbf{a} / / \mathbf{l} / / \mathbf{e} /]$ mereka.

Data 16

Raksasa itu mendengar doa [/d/ /o/ /w/ $/ \mathrm{a} /]$ suami istri itu.

Data 17

Raksasa itu kemudian $[/ \mathbf{k} / / \mathbf{\varepsilon} / / \mathbf{m} / / \mathbf{u} / / \mathbf{d} /$ $/ \mathbf{i} / / \mathbf{a} / / \mathbf{l} /$ ]

Data 18

memberi mereka biji $[/ \mathbf{b} / / \boldsymbol{\varepsilon} / / \mathbf{h} / / \boldsymbol{\varepsilon} /]$ mentimun.

Data 19

"Tanamlah [tahamlah] biji [beje] ini.

Data 20

Nanti kau [koa] akan mendapatkan

Data 21

seorang [seweran] anak perempuan,"

Data 22

kata Raksasa. "Terima kasih, Raksasa," kata suami istri itu. "Tapi ada syaratnya [syaray.
Data 23

Pada usia [usuan] 17 [tuhubelas] tahun

Data 24

anak itu harus kalian serahkan [scraykan] padaku," sahut Raksasa.

Data 25

Suami istri [istre] itu sangat merindukan seorang anak.

Data 26

Karena [kerena] itu

Data 27

tanpa [taypa] berpikir

Data 28

panjang [panhay] mereka setuju.

Data 29

Suami istri [istre] petani itu

Data 30

kemudian [kemuydian]

Data 31

menanam [menanak] biji-biji mentimun itu.

Data 32

Setiap [sctuap] hari mereka merawat

Data 33

tanaman [tanaham] yang mulai tumbuh itu dengan sebaik mungkin.

Data 34

Berbulan-bulan kemudian [kemudiā]

Data 35

tumbuhlah [tumbuhaylah] sebuah mentimun berwarna keemasan. 
Data 36

Buah mentimun itu semakin lama semakin besar [berar]

Data 37

dan berat [betar].

Data 38

Ketika buah itu masak, mereka memetiknya [memetinnya].

Data 39

Dengan hati-hati mereka memotong [memoto] buah itu.

Data 40

Betapa terkejutnya [terkekuanña] mereka, di dalam buah itu

Data 41

mereka menemukan [menckua] bayi perempuan

Data 42

yang sangat cantik [kantik].

Data 43

Suami istri [istre] itu sangat bahagia.

Data 44

Mereka memberi [membere] nama bayi itu Timun [tuan] Mas.

Data 45

Tahun [tahuy]

Data 46

demi tahun [tahuy] berlalu. Timun Mas

Data 47

tumbuh menjadi gadis yang cantik [kantik].

Data 48

Kedua orang tuanya [tuanña] sangat
Data 49

bangga padanya [padanña]. Tapi mereka menjadi sangat takut.

Data 50

Karena pada ulang tahun Timun Mas yang ke-17 [tuhubelas], sang raksasa datang kembali.

Data 51

Raksasa itu menangih [menahe]

Data 52

janji [hanji] untuk mengambil Timun Mas.

Berdasarkan data hasil transkripsi fonetis di atas dapat diidentifikasi perbedaan-perbedan pengucapan pada penutur Filipina yang ditemukan, yaitu:

Perubahan fonem /i/ menjadi / $/$ l

Pada pasangan minimal, pada pasangan kata:

misa - bisa $\rightarrow$ [besa] - [besa]

Pada teks, pada kata-kata:

istri $\rightarrow$ [istre]

biji $\rightarrow$ [bcje]

memberi $\rightarrow$ [member $]$

menangih $\rightarrow$ [menah $\varepsilon]$

Perubahan fonem $/ \mathrm{j} /$ menjadi $/ \mathrm{h} /$

Pada teks, pada kata-kata:

saja $\rightarrow$ [saha]

biji $\rightarrow$ [bche]

tujuhbelas $\rightarrow$ [tuhubelas]

panjang $\rightarrow$ [panhay]

menangih $\rightarrow$ [menahe]

janji $\rightarrow$ [hanji]

Penambahan $/ \eta /$ pada pengucapan

kemudian $\rightarrow$ [kemudiay]

syaratnya $\rightarrow$ [syaranña]

serahkan $\rightarrow$ [scrajkan]

tanpa

[tanpa] 
tumbuhlah $\rightarrow$ [tumbuhaylah]

memetiknya $\rightarrow$ [memetinña]

terkejutnya $\rightarrow$ [terkekuanña]

tahun $\rightarrow$ [tahuy]

berdoa $\rightarrow$ [berdowa]

tuanya $\rightarrow$ [tuanña]

padanya $\rightarrow$ [padanña]

Penghilangan fonem, contohnya:

dikaruniai $\rightarrow$ [karunia]

memotong $\rightarrow$ [memoto]

Perubahan lainnya, baik yang mengalami proses metatesis (penukaran posisi fonem) atau berkombinasi dengan perubahan identitas konsonan, yaitu:

$\begin{array}{ll}\text { hiduplah } & \rightarrow \text { [hidupha] } \\ \text { hutan } & \rightarrow \text { [hulat] } \\ \text { pada } & \rightarrow \text { [dapa] } \\ \text { tanamlah } & \rightarrow \text { [tahamlah] } \\ \text { kau } & \rightarrow \text { [koa] } \\ \text { seorang } & \rightarrow \text { [sewcran] } \\ \text { usia } & \rightarrow \text { [usuan] } \\ \text { karena } & \rightarrow \text { [kerena] } \\ \text { terkejutnya } & \rightarrow \text { [tcrkekuanña] } \\ \text { berat } & \rightarrow \text { [betar] } \\ \text { menemukan } & \rightarrow \text { [menekua] } \\ \text { cantik } & \rightarrow \text { [kantik] } \\ \text { timun } & \rightarrow \text { [tuan] } \\ \text { besar } & \rightarrow \text { [berar] }\end{array}$

Dari data-data yang dikumpulkan, terdapat beberapa hal yang menjadi acuan penyebab perbedaan dalam membaca teks yang diberikan. Hal tersebut antara lain sebagai berikut ini. Pertama, cara membaca yang banyak mengubah huruf bisa saja dipengaruhi oleh struktur alfabet yang dimiliki oleh orang Filipina. Intonasi dan aksen pengucapan dipengaruhi tempat bermukim. Sebagai contoh: /e/ tidak dibaca sebagai /e/ melainkan dengan $/ \varepsilon /$. /n/ yang terletak di akhir sebuah kata akan terbaca $/ \mathrm{y} /$. Hal tersebut dapat dikaitkan dengan adanya perbedaan sistem fonem antara bahasa Indonesia dan bahasa Filipina yang karakternya disajikan pada Tabel 1 di bawah ini.

Tabel 1. Sistem Alfabet dan Fonem Bahasa Filipina

\begin{tabular}{|c|c|c|c|c|c|}
\hline $\begin{array}{l}\text { Huruf } \\
\text { besar }\end{array}$ & $\begin{array}{c}\text { Huruf } \\
\text { kecil }\end{array}$ & $\underline{\text { IPA }}$ & $\begin{array}{l}\text { Huruf } \\
\text { besar }\end{array}$ & $\begin{array}{c}\text { Huruf } \\
\text { kecil }\end{array}$ & $\underline{\text { IPA }}$ \\
\hline $\mathbf{A}$ & $\mathrm{a}$ & $/ \varepsilon \mathrm{I} /$ & $\tilde{N}$ & $\tilde{\mathrm{n}}$ & /'c.ne/ \\
\hline B & $\mathrm{b}$ & /bi:/ & $\mathrm{Ng}$ & ng & /'en.dzi:/ \\
\hline C & $\mathrm{c}$ & /ci:/ & $\mathrm{O}$ & o & /ou/ \\
\hline D & $\mathrm{d}$ & /di:/ & $\mathrm{P}$ & $\mathrm{p}$ & /pi:/ \\
\hline $\mathbf{E}$ & $\mathrm{e}$ & /i:/ & Q & $q$ & /kju:/ \\
\hline $\mathbf{F}$ & $\mathrm{f}$ & /عf/ & $\mathrm{R}$ & $\mathrm{r}$ & /ar/ \\
\hline $\mathbf{G}$ & g & /dzi:/ & $S$ & $\mathrm{~s}$ & $/ \varepsilon \mathrm{s} /$ \\
\hline $\mathbf{H}$ & $\mathrm{h}$ & $/ \varepsilon \operatorname{It} \int /$ & $\mathrm{T}$ & $\mathrm{t}$ & $/ \mathrm{ti}: /$ \\
\hline I & $\mathrm{i}$ & $/ a j /$ & $\mathrm{U}$ & $\mathrm{u}$ & /ju:/ \\
\hline $\mathbf{J}$ & $\mathrm{j}$ & $/ \mathrm{d} z \varepsilon \mathrm{j} /$ & V & $\mathrm{v}$ & /vi:/ \\
\hline K & $\mathrm{k}$ & $/ \mathrm{kcj} /$ & $\mathrm{W}$ & w & /'do.bəl.ju:/ \\
\hline $\mathbf{L}$ & 1 & $/ \varepsilon \mathrm{l} /$ & $\mathrm{X}$ & $\mathrm{x}$ & /عks/ \\
\hline M & $\mathrm{m}$ & $/ \varepsilon \mathrm{cm} /$ & $\mathrm{Y}$ & $\mathrm{y}$ & /vaj/ \\
\hline $\mathbf{N}$ & $\mathrm{n}$ & $/ \varepsilon \mathrm{n} /$ & $\mathrm{Z}$ & $\mathrm{z}$ & /zi:/ \\
\hline
\end{tabular}

Kedua, gabungan-gabungan huruf menyebabkan adanya pertukaran huruf yang terjadi saat membaca. Hal itu dikaitkan dengan adanya perbedaan data pertama yang berupa pasangan kata. Dalam rekaman video kedua, terlihat kesulitan dari narasumber pada beberapa kata. Misalnya, pada kata hiduplah yang diucapkan dengan [hidupha] yang mana deretan fonem /plah/ menjadi [pha]. Ini menunjukkan penutur kesulitan mengucapkan gabungan fonem tersebut karena tidak terdapat dalam bahasanya. Ini sesuai dengan informasi narasumber sendiri bahwa perubahan pengucapan gabungan fonem berkaitan dengan adanya beberapa huruf yang tidak 
mereka kenal atau tidak digunakan pada kata-kata dalam bahasa Filipina.

Berdasarkan transkripsi fonetis, diperoleh fakta bahwa terdapat perubahan fonem, penambahan fonem, dan penghilangan fonem suatu kata dalam bahasa Indonesia yang dituturkan oleh penutur asing dari Filipina. Fenomena ini sejalan dengan hasil penelitian Inderasari \& Agustina (2017). Perubahan fonem antara lain adanya tekanan kuat dalam melafalkan fonem /r/. Hal ini memungkinkan berkaitan dengan hasil penelitian Parwati (2015) yang menunjukkan adanya perbedaan pengucapan fonem getar alveolar dalam bahasa Indonesia antara laki-laki dan perempuan.

Temuan penelitian ini juga menunjukkan adanya kesamaan dengan hasil penelitian Adityarini, Pastika, \& Sedeng (2019) yang menemukan adanya interferensi bahasa orang Eropa terhadap bahasa Indonesia yang disebabkan oleh adanya perbedaan pelafalan sebuah bunyi vokal atau bunyi konsonan yang sama pada kedua bahasa tersebut. Adapun dari penelitian ini ada interferensi bahasa Filipina. Akan tetapi, hasil penelitian ini juga ada perbedaan dengan temuan para peneliti tersebut. Sebelumnya terdapat pula penelitian perihal intonasi pembelajar BIPA pada orang Eropa saat membacakan teks bahasa Indonesia. Beberapa hasil yang berbeda dengan penelitian ini dengan penelitian terhadap orang Eropa adalah dari segi bunyi yang dihasilkan pada fonem tertentu.

Hasil penelitian ini juga menunjukkan bahwa perubahan pengucapan fonem bahasa Indonesia dipengaruhi oleh fonem bahasa penuturnya. Hal ini relevan dengan hasil penelitian Mappau (2014). Adapun berdasarkan hasil wawancara dengan informan, pengaruh tersebut disebabkan oleh faktor kesulitan penutur untuk mengucapkan gabungan atau deretan fonem tertentu. Hal ini sejalan dengan hasil penelitian Nawari (2019) bahwa bunyi-bunyi bahasa Indonesia tertentu pada posisi tertentu sulit dilafalkan dengan benar oleh penutur bahasa Arab. Kesulitan yang sama juga dialami penutur asing dari Tiongkok (Wiratsih, 2019).

Temuan lain penelitian ini adalah meskipun ada perubahan pengucapan kata-kata bahasa Indonesia oleh penutur asing dari Filipina, dengan didukung bahasa nonverbal, komunikasi memungkinkan tidak terlalu menjadi kendala yang menimbulkan kesalahpahaman. Hal tersebut disampaikan oleh informan dari pengalamannya berkomunikasi dengan mahasiswa lain. Fakta ini relevan dengan hasil kajian pustaka yang dilakukan Pranowo (2019).

\section{SIMPULAN}

Dari data-data yang dikumpulkan, dapat disimpulkan (1) terjadi perubahan pengucapan fonem pada kata berbahasa Indonesia oleh penutur 
dari Filipina karena dipengaruhi oleh struktur alfabet yang dimiliki berbeda dengan Indonesia; (2) intonasi dan aksen pengucapan dipengaruhi lingkungan tempat tinggal penutur; (3) gabungan-gabungan huruf menyebabkan adanya pertukaran huruf yang terjadi pada saat mengucapkan kata maupun membaca teks.

Penelitian mengenai fonologi ini masih bisa dilanjutkan dengan menggunakan responden dari negara lain, karena setiap penutur asing memungkinkan memiliki variasi pengucapan yang menyebabkan ujaran yang berbeda terhadap bahasa Indonesia.

\section{REFERENSI}

Adityarini, I.A.P. (2020). Interferensi Fonologi pada Pemelajar BIPA Asal Eropa di Bali. Jurnal Aksara, 32 (1), $167-186$.

Gross, H. (1998). Einführung in die germanistische Linguistik. München: iudicium Verlag GmbH. Inderasari, E. \& Agustina, T. (2017). Pembelajaran Bahasa Indonesia pada Mahasiswa Asing dalam Program BIPA IAIN Surakarta. Jurnal Pendidikan Bahasa dan Sastra Indonesia, 6 (2), 6-15.

Mappau, R. (2014). Variasi Fonologi

Bahasa Indonesia pada

Komunitas Penutur Bahasa

Makassar. Sawerigading, 20 (2), 291-300.

Marsono. (1999). Fonetik. Yogyakarta: Gadjah Mada University Press.

Nawari, A. (2019) Analisis Pelafalan Bunyi Bahasa Indonesia Oleh Penutur Bahasa Arab di
Universitas Sousse, Tunisia. Prosiding Konferensi Internasional Pengajaran Bahasa Indonesia bagi Penutur Asing (KIPBIPA) XI 2019, 487500.

Parwati, S.A.P.E. (2015). Realisasi Fonetis Konsonan Getar Alveolar Bahasa Indonesia pada Laki-Laki dan Perempuan Dewasa. Aksara, 27 (1), 37-47.

Pranowo. (2019). Bahasa Nonverbal Sebagai Konteks dalam Pembelajaran BIPA: Kajian Pragmatik Edukasional. Jurnal Bahasa Indonesia Bagi Penutur Asing, 1 (2), 72-82.

Samsuri. (1985). Analisis Bahasa. Jakarta: Erlangga.

Sudaryanto. (2015). Metode dan Aneka Teknik Analisis Bahasa. Yogyakarta: Sanata Dharma University Press.

Verhaar, J.M.W. (2001). Asas-asas Linguistik Umum. Yogyakarta: Gadjah Mada University Press.

Wiratsih, W. (2019). Analisis Kesulitan Pelafalan Konsonan Bahasa Indonesia (Studi Kasus terhadap Pemelajar BIPA Asal Tiongkok di Universitas Atma Jaya Yogyakarta). Jurnal Kredo: Jurnal Ilmiah Bahasa dan Sastra, 2 (2), 242-255.

BASASTRA Jurnal Bahasa, Sastra, dan Pengajarannya

Volume 9 Nomor 1, April 2021, P-ISSN 2302-6405, E-ISSN 2714-9765 